\title{
Study the Performance of Solar Water Heater with Various Loads
}

\author{
Ghassan S. EL-MASRY*, Mustafa EL-MUSBAHI, Benur MAATUG \\ Department of Mechanical Engineering, Elmergib University, Garaboulli, Libya
}

DOI: https://doi.org/10.21467/proceedings.4.2

* Corresponding author email: gsalmasri@elmergib.edu.ly

\begin{abstract}
The performance of a certain type of solar heater was studied by install, assemble solar heater and the installation of different measuring devices, such as water flow meter and temperature meters for water inside, outside, and measuring the temperature of the atmosphere and a measure of the amount of solar radiation, all of these devices connected to a device that stores this data every 5 minutes In the form of averages or totals.

The first tests were carried out by consumption of the water in the early morning (immediately after sunrise). In the second period, the consumption of water was at the end of the day (before sunset). The third period was at noon (midday)

TRNSYS, a specialized program in simulating solar thermal processes, TRNSYS can used to connect thermal system components in any form, solving differential equations and facilitating the output of information.

TRNSYS works to compensate the practical experience with a fully simulated theory that saves time and effort and gives us the desired results of the practical experiment. The program data is the solar heater characteristics of the experiment, the period to be tested and the amount of water to be consumed.

The study explains that the best time to increase the amount of energy extracted the water must drained at the afternoon period.
\end{abstract}

Keywords: solar heater, solar energy, simulation system, consumed period, change of loads, alternative energies

\section{Introduction}

A field study was conducted for a complex heater at the Solar Energy Research and Studies Centre in Tajoura, where integrated measuring devices were used to study and analyse the solar thermal performance of the solar heater. The study period lasted more than two months and was divided into three stages. The water was withdrawn in the first stage in the morning, the second stage just before sunset and then in the final stage, the drawn were during the afternoon. It will discuss the specifications of the solar heater, the measuring instruments and the methods of testing approved for the solar heater. In this study, it was based on the international standard for testing solar heaters, referred as ISO 9459-2 for the evaluation of solar heater under study, issued by the International Organization for Standardization (ISO)

(C) 2018 Copyright held by the author(s). Published by AIJR Publisher in Proceedings of First Conference for Engineering

Sciences and Technology (CEST-2018), September 25-27, 2018, vol. 2 .
This is an open access article under Creative Commons Attribution-NonCommercial 4.0 International (CC BY-NC 4.0) license, which permits any non-commercial use, distribution, adaptation, and reproduction in any medium, as long as the original work is properly cited. ISBN: 978-81-936820-6-7 


\section{Specifications}

For data that helps to obtain the thermal performance of the heater, the solar heater is provided with measurement sensors connected to the Data Acquisition System, which can sensor data from sensors every 10 seconds and store it at the end of every five minutes in the form of cumulative or average values by The nature and characteristics of this data.

In this study, a range of variables were measured: the temperature of the water inlet to the reservoir $\mathrm{T}_{\mathrm{i}}$, the outlet temperature $\mathrm{T}_{\mathrm{o}}$, the temperature of the air surrounding the heater Tamp, the amount of hot water consumed $\mathrm{M}$, and the intensity of the total solar radiation falling on the surface of the complex $G_{\text {sol, }}$, For each five minutes throughout the day in the form of temperature averages and cumulative values of the radiation falling on the surface of the collector and water consumed. The data device calculates the amount of total thermal energy acquired for hot water $\mathrm{Q}_{\mathrm{t}}$.

\section{Solar heaters}

The heater consists of a compound with an assembly area of $3.024 \mathrm{~m} 2$ and a reservoir of horizontal type, with an auxiliary electric coil installed manually to meet the shortage of thermal energy resulting from the absence of the sun at night or in the days when the clouds are abundant. The collector and the reservoir are connected to each other by connecting pipes to suit the natural flow system. The system was directed to the true south at an angle of $40^{\circ}$ from the horizontal

Table 1 Specifications of solar heater

\begin{tabular}{|l|l|}
\hline Solar heater & Natural flow closed circuit \\
\hline Type of heater & 200 liters \\
\hline The total capacity & $3.024 \mathrm{~m} 2$ \\
\hline The solar collector area & $15 \mathrm{~mm}$ diameter copper tube \\
\hline Collector pipe & glass thermally treated thickness of $3 \mathrm{~mm}$ \\
\hline Collector glass surface & Selective Coating (Black Chrome) \\
\hline Absorption Surface Coating & glass wool thickness of $30 \mathrm{~mm}$ \\
\hline Collector insulation & horizontal ring type \\
\hline Hot water tank & Polyurethane foam $45 \mathrm{~mm}$ thick \\
\hline Hot water tank insulator & \\
\hline
\end{tabular}

Figure $1(\mathrm{a}, \mathrm{b})$ shows the solar heater diagram used in the experiment 


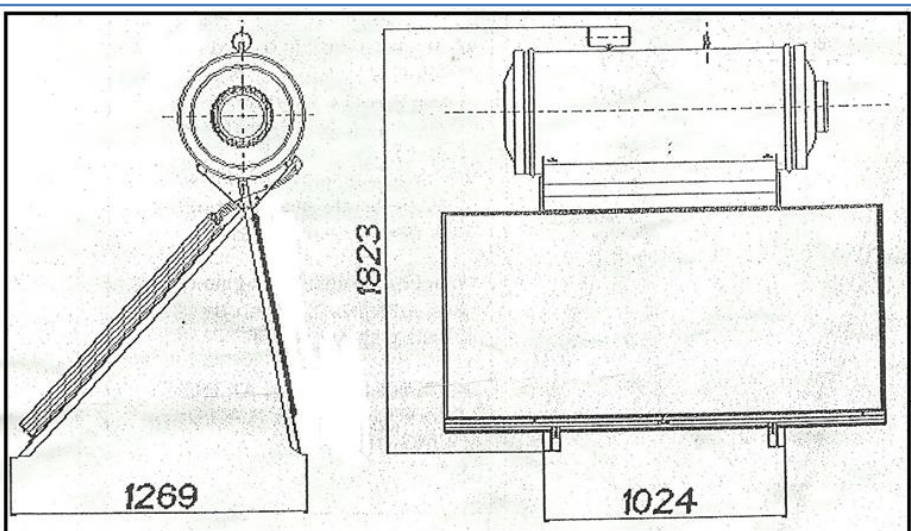

Figure 1a Cross section of the solar heater (from catalog)
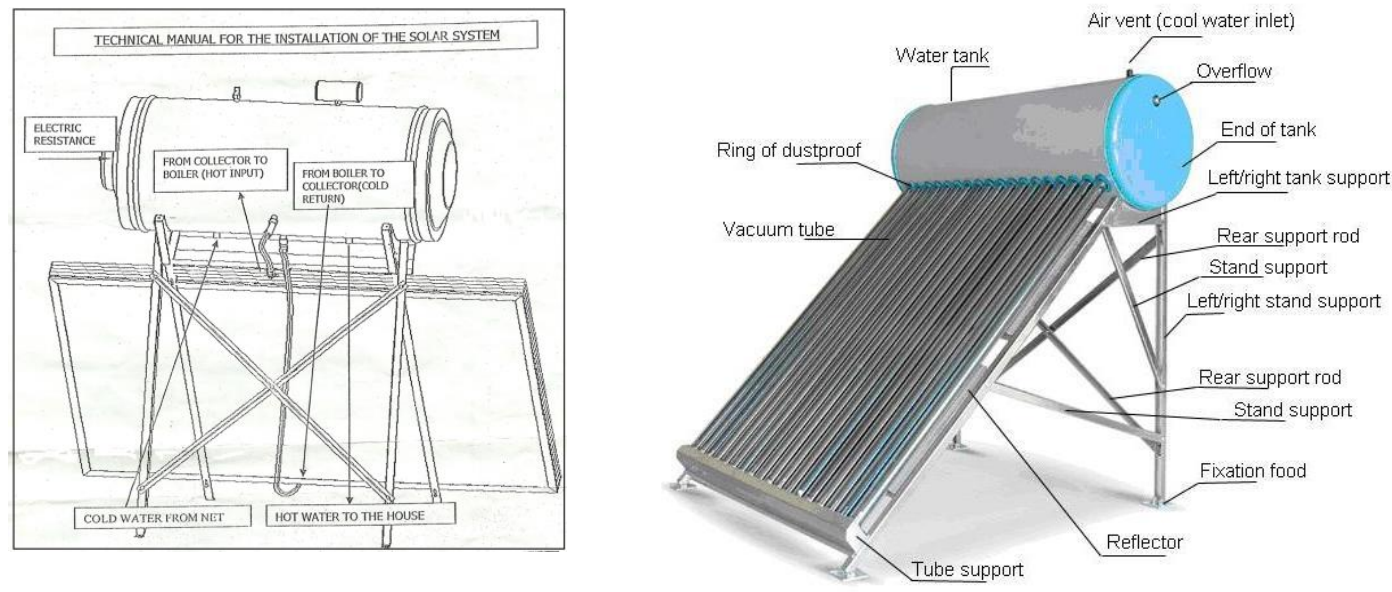

Figure $\mathbf{1 b}$ a synthesis of the solar heater (the right figure from catalog)

\section{$4 \quad$ Range of test conditions}

The test results are prepared in this system using a special model. The input / output graph and the temperature increase are also explained and presented.

Test results are not used to report on the performance of the heater under test. It is represented an intermediate stage in the test and is only used as entries for calculations.

Test results include daily system productivity for different values of $H$ and $\left(T_{a}\right.$ (day) $\left.-T_{c}\right)$. Therefore the performance of the solar water heating system can be represented by the following equation[2]

$\mathrm{Q}=\mathrm{a}_{1} \mathrm{H}+\mathrm{a}_{2}\left[\mathrm{~T}_{\mathrm{a}(\mathrm{av})}-\mathrm{T}_{\mathrm{c}}\right]+\mathrm{a}_{3}$

The coefficient $\left(a_{1}, a_{2}, a_{3}\right)$ of the system is determined from the test results' using the linear correlation model, whereas $(\mathrm{Q})$ means or refers to the net solar energy obtained by the thermal tank during the day, (Q) is calculated by total hot water drawn or extracted according to the test defined.

In addition, the results of the test containing the temperature $\left(T_{a \text { (day) }}-T_{c}\right)$ for water for different values of $(\mathrm{H})$ and $\left(\mathrm{T}_{\mathrm{a}(\mathrm{day})}-\mathrm{T}_{\mathrm{c}}\right)$ by the following equation [2]: 
$\mathrm{T}_{\mathrm{d}(\max )}-\mathrm{T}_{\mathrm{c}}=\mathrm{b}_{1} \mathrm{H}+\mathrm{b}_{2}\left[\mathrm{~T}_{\mathrm{a}(\mathrm{day})}-\mathrm{T}_{\mathrm{c}}\right]+\mathrm{b}_{3}$

The coefficients $\left(b_{1}, b_{2}, b_{3}\right)$ are determined from the test results using the linear correlation model, while $T_{d(\max )}$ in the equation refers to the maximum temperature of the extracted water. And the results and curves were as follows:

It was in the withdrawn curves for the morning period for three days as shown in Figure 2 (A, $\mathrm{B}, \mathrm{C})$ :

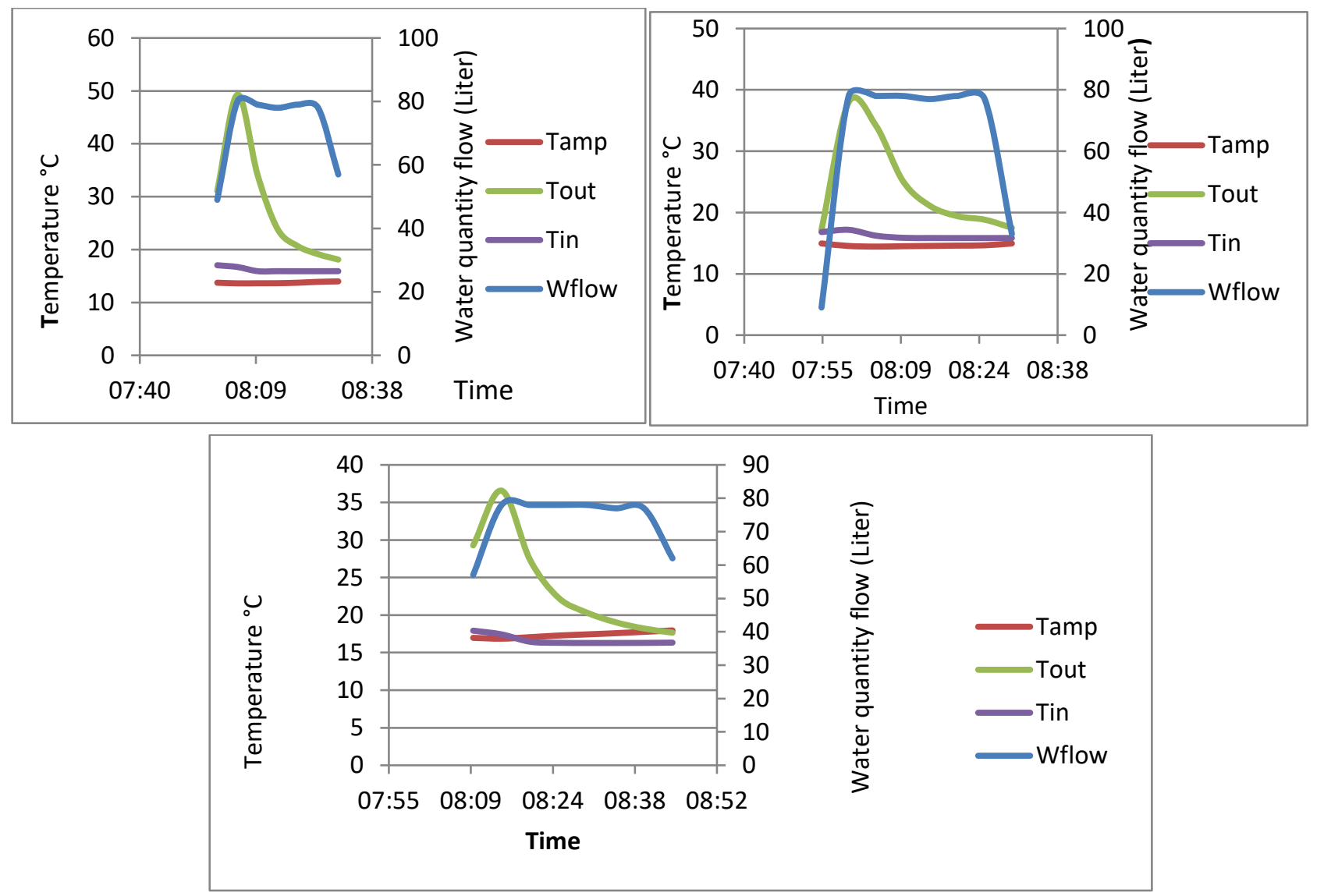

Figure $2 \boldsymbol{a}, \boldsymbol{b}, \mathbf{c}$ withdrawn curves for the morning period

Then in the evening curves for three days as shown in Figure $3(a, b, c)$ : 
Study the Performance of Solar Water Heater with Various Loads
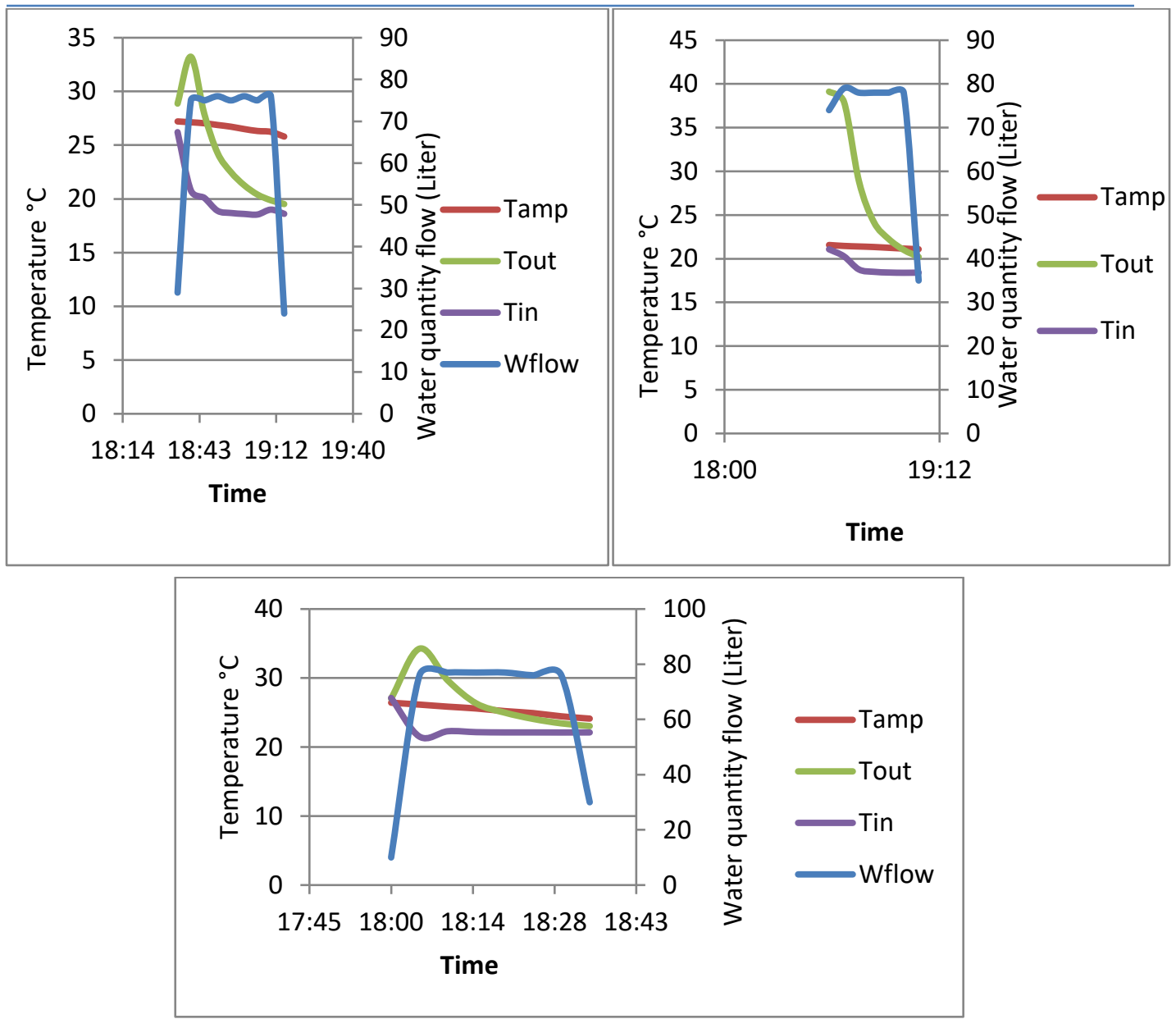

Figure 3 a,b,c Draw curves during the evening

In the afternoon for three days, as shown in Figure 4 (a, b, c):

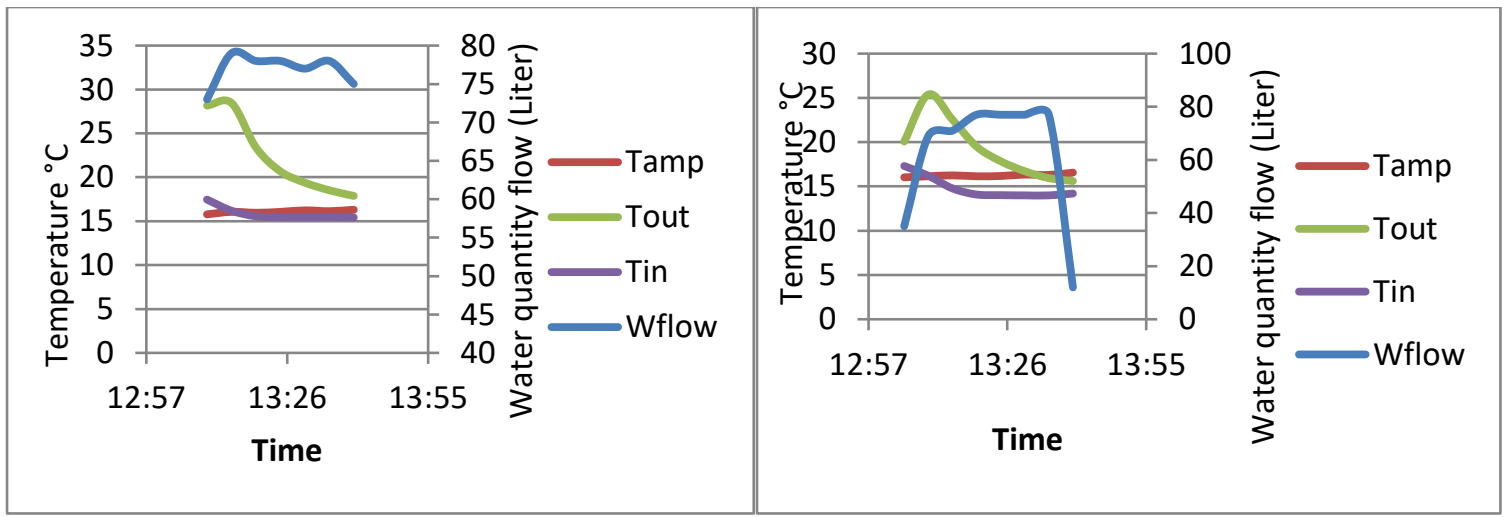

Figure 4a,b Draw curves during the afternoon 


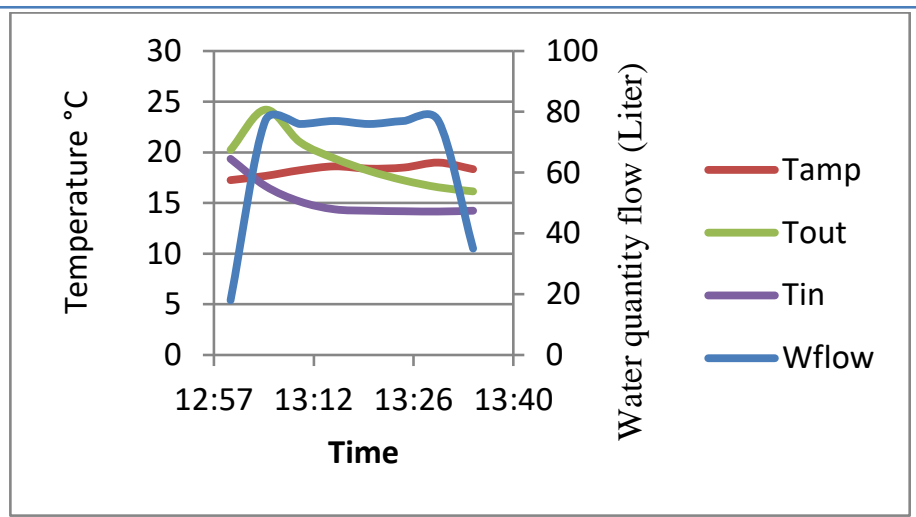

Figure 4c Draw curves during the afternoon

\section{Representing the simulation program results}

After introducing the specifications of the solar heater used in the experiment and determining the required temperature, as the temperature at which the draw water should come out, and give all the data to the program, the results are in curves as follows:

Temperatures
- Outlet

Heat transfer rates

-Outet

- label

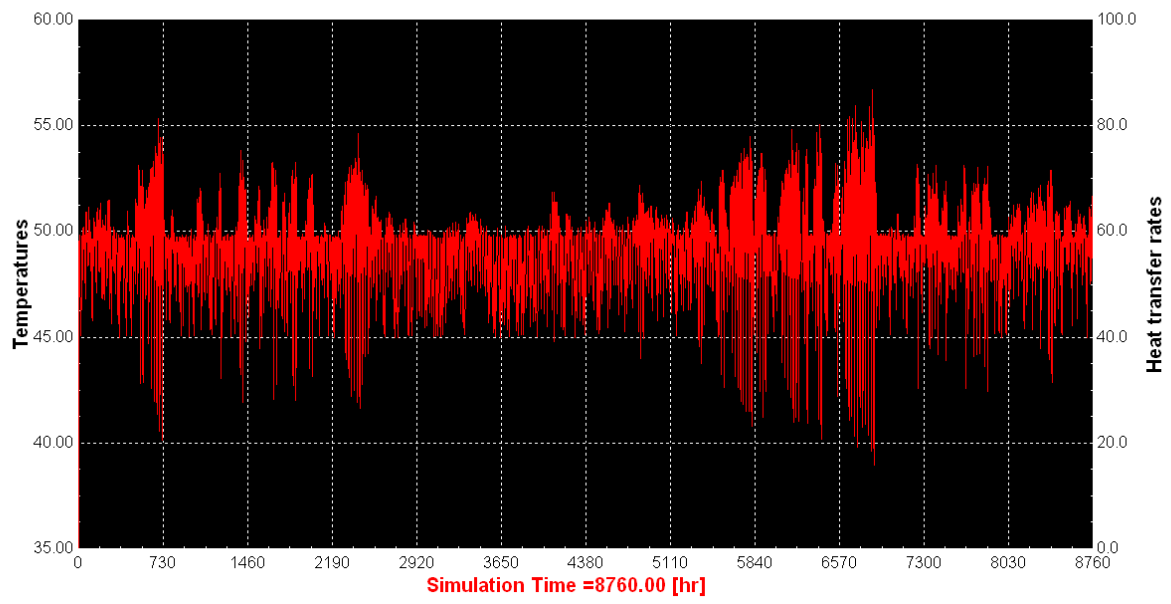

Figure 5 Comparison between the temperature of the withdrawn water and the rate of heat transfer and the simulation time over a whole year

Figure 5 shows that the higher the rate of heat transfer, the higher the temperature of the withdrawn water, that mean the relationship between the rate of heat transfer and the temperature of the withdrawn water is a direct relationship. 


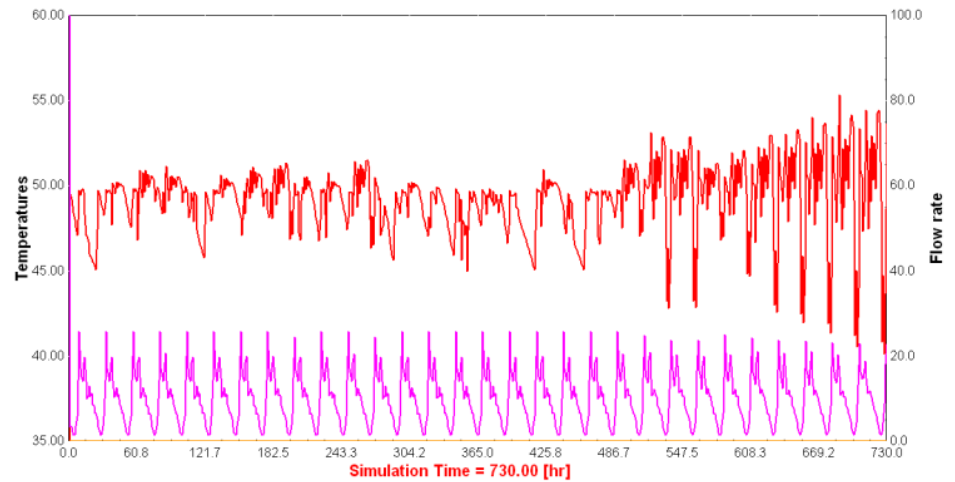

Figure 6 The relation between the draw water temperature and the water flow rate (the drag rate) and the simulation time which is a full month

In Figure (6), where the rate of drawn water was constant in the morning period over a whole month, but note that the temperature of withdrawn water increases by the end of the month, due to the fact that the solar radiation increases at the end of this month and based on the increase in The radiation increases the temperature of the drawn water.

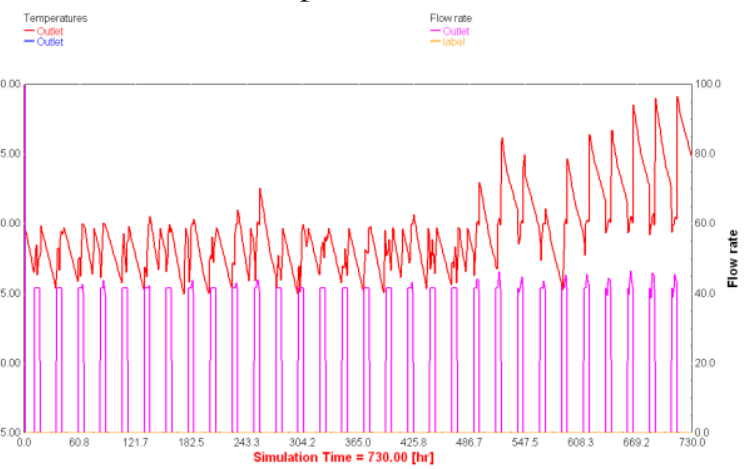

Figure 7a The relationship between the temperature of the withdrawn water and the drag rate and the time that represents a full month and the draw were in the evening, ie before sunset

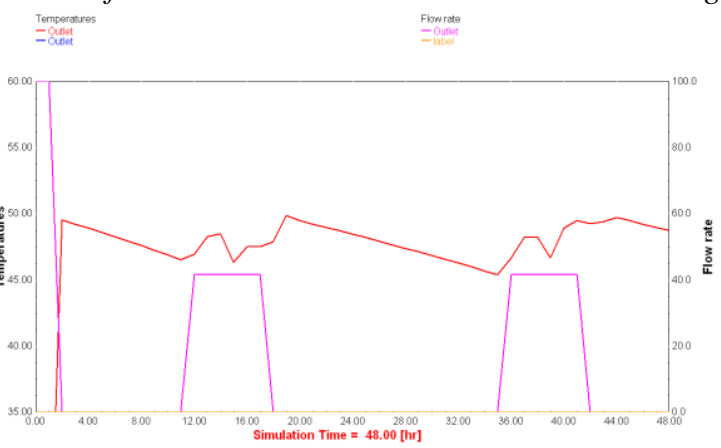

Figure $\mathbf{7 b}$ The relationship between the temperature of the drawn water and the flow rate and the simulation time, which is two full days

In Figure $7 \mathrm{a}, \mathrm{b}$, the draw here is a complete withdrawal of the load, i.e., a draw along the day from 11 am to $6 \mathrm{pm}$ 


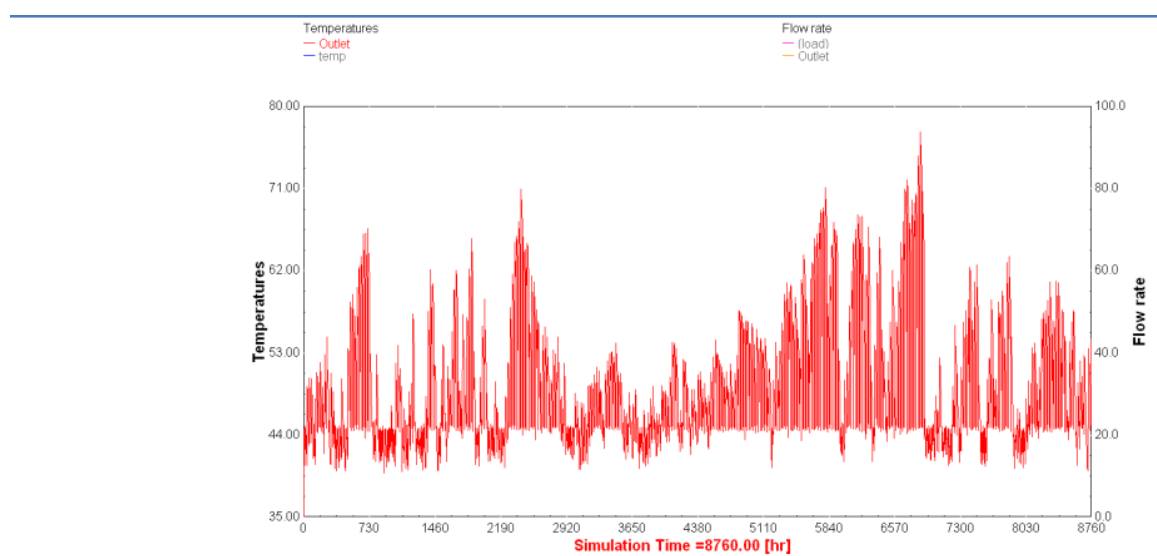

Figure 8 The relationship between the temperature of the drawn water and the flow rate at afternoon and the simulation time which is equivalent to one year

Figure 8 shows that at the afternoon there are increase of temperature of drawn water

\section{Conclusion}

This study explains the best time to drained the hot water from the solar collectors as shown in Figures 2,3,4 the experiment for three days for each period and the simulation program as shown in figure 7,8 . This study shows the variation of results when the consumption of water is changed from morning, afternoon and evening. The best time to increase the amount of energy extracted and the temperature is at the afternoon period.

\section{Reference}

[1] Strategical report for renewable energy-Nation board for scientific research - Libya- Nation Week For scientific and Technology 2006

[2] ASHREA 93,77 fundamentals.

[3] ASHRAE. 1991a. Active solar heating systems installation manual. 